\title{
The Role of Source-Sink Relations between Photosynthetic and Assimilate-Consuming Organs in Regulation of Plant Photosynthesis
}

\author{
VI Chikov* \\ Kazan Institute of Biochemistry and Biophysics, Russia
}

Submission: February 08, 2017; Published: March 27, 2017

"Corresponding author: VI Chikov, Kazan Institute of Biochemistry and Biophysics, Russian Academy of Sciences, P.O. 30, Kazan 420503, Russia, Email: vichikov@bk.ru

\begin{abstract}
Cause and effect relationships between chloroplast photochemical reactions, $\mathrm{CO}_{2}$ assimilation and oxygen photosynthetic metabolism, transport of sugars in the phloem, apoplastic invertase and leaf stomata activity have been established. Regulation of photosynthesis at the level of an assimilate donor leaf with the change of illumination or export of products of photosynthesis is effectuated as follows. In case of deficiency of products of chloroplast photochemical reactions there occurs incomplete regeneration of resulting primary $\mathrm{CO}_{2}$ fixation products and rapid accumulation of oxygenated substances in cells, vacuoles and the apoplast of the leaf. Apoplastic fluid pH decrease activates the invertase and intensifies the sucrose splitting in the apoplast, which increases the osmolality of extracellular environment that is increased approaching the guard cells, where the main evaporation of water takes place. The osmolality of extracellular environment decreases the turgor of the guard cells and increases the resistance of $\mathrm{CO}_{2}$ diffusion into the leaf.
\end{abstract}

Keywords: Assimilate transport; Apoplast; Stomata; Invertase; Chloroplast

Abbreviation: DAR: Donor-Acceptor Relations; ETC: Electron Transport Chai; Fd: Ferredoxin; PCM: Photosynthetic Carbon Metabolism; PES: Phosphorus Esters of Sugars; PR: Photorespiration; 3-PGA: 3-Phosphoglycerate; Rubp: Ribulose 1,5-Bisphosphate; Rubpco: Ribulose-1,5Bisphosphate Carboxylase/Oxigenase

\section{Introduction}

In the fifties of the $20^{\text {th }}$ century the entomologist of Kazan agricultural institute K.I. Popov found out that plants whose leaves are damaged by insects grow faster afterwards [1]. In order to clarify this phenomenon he sent the postgraduate student Yu.S. Karpilov to Kazan State University to get acquainted with the method of photosynthesis measurement with labelled ${ }^{14} \mathrm{CO}_{2}$. The study started with the corn as an agricultural plant popular at that time. In the early experiments Yu.S. Karpilov discovered an unusual content of primary products of photosynthesis in the corn (C-4 type) and all his further efforts were aimed at the solution of this problem and donor-acceptor relations (DAR) were moved aside.

The next important stage in DAR problem investigation started with the discovery of the influence of DAR disturbance on photorespiration (Warburg effect) [2,3]. It was demonstrated that the decrease of weight of assimilate consuming organs (flowers, fruit or draws) causes PR intensification.
However, Lenz, Hall and Brady did not try reducing the surface of plant leaves, did not study the PCM and did not relate the obtained results to the processes of mass substance transportation in the whole plant. As a result, the problem of DAR remained unattended by the researchers, though the terms sink - source may be found in literature, they were not related to the processes of DAR as the principal regulatory factor, but remained as particular reactions (regional authorities) not making part of the whole plant physiology.

It is worth mentioning that DAR is the most suitable approach to photosynthesis regulation study. But the research has to be conducted on a mature leaf at the stage of intensive accumulation of the substance in the reproductive organs of plants (for example, gramineous plants with spikes or cotton plant with multiple seed cases). At that stage plants have a lot of assimilate accepting organs, which rapidly increase their mass and, consequently, consume a big amount of photosynthesis 
products. If a fragment of such assimilate accepting organs is removed, great excess of products of photosynthesis emerges. And vice versa, the removal of a fragment of mature leaves causes growth of assimilate "demand" and the increased efflux from the leaf may even lead to the destruction of photosynthetic apparatus structures [4]. It is essential that the study subject, the mature leaf, remains in its absolute native state.

This article summarizes the results of multi-year research on PCM m with ${ }^{14} \mathrm{CO}_{2}$ obtained mostly with the use of cotton plant and wheat whose DAR are clearly revealed during the reproductive phase of development.

The Influence of DAR Disturbance on Correspondence between Photosynthesis and Photorespiration in the Donor Leaf

The first experiments on the influence of DAR on gaseous interchange between plants revealed inverse relationship between PR and export function of the leaf [5]. If a plant was deprived of fruit, the PR increased (Table 1). And vice versa, if a fragment of mature assimilate donor leaves was removed, the PR decreased. The greatest changes in $\mathrm{CO}_{2}$ absorption were observed when the leaf gaseous interchange was measured in the environment of increased oxygen concentration (21\%), i.e. in case of glycolate production and PR functioning in C-3 leaves.

Table 1: Effect of removing leaves or fruit of cotton on photosynthesis and the Warburg effect.

\begin{tabular}{|c|c|c|c|}
\hline \multirow{2}{*}{$\begin{array}{c}\text { Option } \\
\text { Experience }\end{array}$} & \multicolumn{2}{|c|}{$\begin{array}{l}\text { Photosynthesis }\left(\mathrm{mg} \mathrm{CO}_{2} \mathrm{dc}^{-2}\right. \\
\left.\mathrm{h}^{-1}\right)\end{array}$} & \multirow{2}{*}{$\begin{array}{c}\text { Warburg } \\
\text { Effect(\% to } \\
1 \% 02)\end{array}$} \\
\hline & $1 \% \mathrm{O}_{2}$ & $21 \% \mathrm{O}_{2}$ & \\
\hline Control & $30.6 \pm 4.3$ & $20.3 \pm 1.8$ & 33.7 \\
\hline Removing fruit & $15.4 \pm 3.7$ & $7.2 \pm 1.7$ & 53.2 \\
\hline $\begin{array}{l}\text { Removing } \\
\text { leaves }\end{array}$ & $46.5 \pm 6.9$ & $35.3 \pm 3.7$ & 24.1 \\
\hline
\end{tabular}

The reduction of assimilate-consuming organs weight was followed by activation of growth processes [6] in all organs of the plant (especially in the root system) which signalled triggering of adaptation mechanisms of metabolic process regulation in the whole plant. As it is a well-known fact, that Warburg effect is related to glycolate metabolism [7], which is considered to be produced in oxygenase reaction of RUBISCO in chloroplasts, the next stage of our study was dedicated to distribution of $14 \mathrm{C}$ among early products of photosynthesis in order to evaluate the character of PCM change under the influence of DAR disturbance.

\section{The Trend of Photosynthetic Carbon Metabolism and Export Function of the Leaf}

The kinetics experiments with $14 \mathrm{CO}_{2}$ in different concentrations of carbon dioxide $(0.03 \%$ and $0.3 \%)$ showed significant differences $\mathrm{in}^{14} \mathrm{C}$ inclusion into glycolate and products of its metabolism [8]. The key differences are as follows:

A. There are at least two different mechanisms of glycolate production, which differ kinetically in respect of ${ }^{14} \mathrm{C}$ inclusion.
One mechanism is presumably closer to the product of ${ }^{14} \mathrm{CO}_{2^{\prime}}$ fixation and the other one is farther.

B. In case of removal of assimilate accepting organ part the impact of the first source of glycolate production is incremented.

C. Once $\mathrm{CO}_{2}$ concentration rises, the intensity of ${ }^{14} \mathrm{C}$ inclusion into glycolate metabolism products of control plants is decreased while that of experimental plants practically does not change, but the relative role of that channel (in comparison to sugar synthesis) in experimental plants is significantly increased (Table 2).

Table 2: The influence move off fluits on $14 \mathrm{C}$ distribution among some labeled products after $3 \mathrm{~min}{ }^{14} \mathrm{CO} 2$ assimilation (\% radioactivity of water-ethanol soluble fraction) in wheat.

\begin{tabular}{|c|c|c|c|c|}
\hline \multirow{2}{*}{ Compounds } & \multicolumn{3}{|c|}{ C02 Concentration (\%) } \\
\cline { 2 - 5 } & Control & Experiment & Control & Experiment \\
\cline { 2 - 5 } & $48 . \pm 2.1$ & $43.9 \pm 3,4$ & $59.0 \pm 4.1$ & $58.2 \pm 3.6$ \\
\hline Sucroce & $19.1 \pm 0.8$ & $18.8 \pm 1,3$ & $16.4 \pm 2.2$ & $12.1 \pm 1.5$ \\
\hline $\begin{array}{c}\text { Phosphorus } \\
\text { esters of sugars }\end{array}$ & $0.9 \pm 0.1$ & $1.7 \pm 0,2$ & $1.5 \pm 0.3$ & $1.7 \pm 0.2$ \\
\hline Hexoses & $13.0 \pm 1.3$ & $18.3 \pm 1,3$ & $2.2 \pm 0.4$ & $5.1 \pm 0.3$ \\
\hline $\begin{array}{c}\text { Serine, glycine, } \\
\text { glycolate }\end{array}$ & $7.1 \pm 0.6$ & $7.7 \pm 0,5$ & $2.3 \pm 0.2$ & $3.7 \pm 0.3$ \\
\hline $\begin{array}{c}\text { Glicerate, } \\
\text { malate, } \\
\text { aspartate }\end{array}$ & $6.8 \pm 0.8$ & $6.4 \pm 0,7$ & $16.1 \pm 2.6$ & $17.3 \pm 1.7$ \\
\hline $\begin{array}{c}\text { Alanine } \\
\text { Pigments }\end{array}$ & $0.6 \pm 0.1$ & $1.4 \pm 0,2$ & $0.3 \pm 0.1$ & $1.2 \pm 0.2$ \\
\hline $\begin{array}{c}\text { Sucrose/ } \\
\text { hexoses }\end{array}$ & 54.1 & 25.8 & 39.3 & 34.2 \\
\hline $\begin{array}{c}\text { Intensity of } \\
\text { photosynthesis } \\
\text { (CO2•dm-2h-1) }\end{array}$ & $35.6 \pm 1.1$ & $25.1 \pm 2.9$ & $97.3 \pm 5.7$ & $86.7 \pm 7.5$ \\
\hline
\end{tabular}

Great similarity of kinetics of ${ }^{14} \mathrm{C}$ inclusion into glycolate in control and experimental variants of plants with carbon dioxide saturating concentration indicates [9] the production of this compound in the leaves of plants with removed fruit which happens mostly according to the mechanism functioning in the absence of RUBISCO oxygenase (low concentration of $\mathrm{O}_{2}$ and saturating concentration of $\mathrm{CO}_{2}$ ). According to the literature another possible source of glycolate is the transketolase reaction of the Calvin cycle [10] which is realized with superoxide radical [11] produced through the Mehler reaction [12].

Removal of a fragment of consuming organs of the cotton plant led to certain reduction in sucrose synthesis and intensification of generation of glycolate metabolism products and hexoses (Table 3) simultaneously sucrose and hexose radioactivity ratio decreased significantly. This data allowed suggesting the hypothesis of photosynthesis regulation [8], in which the increased stream of oxygen through the glycolate passage in case 
of sugars efflux inhibition from the leaf does not end with the Calvin cycle and the products of glycolate metabolism are used for intensified growth processes in the leaf.

Table 3: Distribution of $14 \mathrm{C}$ among labelled products of photosynthesis in leaves and apoplast of the top and donor parts of a flax shoot whose middle part was exposed to $14 \mathrm{CO} 2$ for 5 minutes (\% to radioactivity of the water-ethanol-soluble fraction).

\begin{tabular}{|c|c|c|c|c|}
\hline \multirow{2}{*}{ Compounds } & \multicolumn{2}{|c|}{ Upper Part } & \multicolumn{2}{c|}{${ }^{14}$ C-donor Part } \\
\cline { 2 - 5 } & Leaves & Apoplast & Leaves & Apoplast \\
\hline Sucrose & $73.5 \pm 0.6$ & $89.7 \pm 0.2$ & $60.9 \pm 0.5$ & $89.6 \pm 0.5$ \\
\hline Hexoses & $4.8 \pm 0.2$ & $0.6 \pm 0.2$ & $3.6 \pm 0.1$ & $0.7 \pm 0.0$ \\
\hline Amino acids & $10.0 \pm 0.6$ & $4.1 \pm 0.2$ & $15.1 \pm 0.3$ & $3.9 \pm 0.4$ \\
\hline Malate & $3.2 \pm 0.2$ & $2.2 \pm 0.1$ & $4.0 \pm 0.1$ & $2.1 \pm 0.1$ \\
\hline $\begin{array}{c}\text { Other } \\
\text { compounds }\end{array}$ & $8.5 \pm 0.2$ & $3.4 \pm 0.8$ & $16.4 \pm 0.7$ & $3.7 \pm 0.1$ \\
\hline $\begin{array}{c}\text { Sucrose/ } \\
\text { Hexoses }\end{array}$ & 15 & 149.5 & 16.9 & 128 \\
\hline \multirow{2}{*}{ Nitrogen-Fertilized Plants } \\
\hline Sucrose & $61.5 \pm 0.3$ & $77.1 \pm 0.5$ & $57.1 \pm 1.0$ & $76.2 \pm 1.1$ \\
\hline Hexoses & $5.3 \pm 0.2$ & $2.1 \pm 0.2$ & $4.2 \pm 0.1$ & $2.0 \pm 0.1$ \\
\hline Amino acids & $15.7 \pm 0.5$ & $11.7 \pm 0.5$ & $17.2 \pm 0.6$ & $11.1 \pm 0.7$ \\
\hline Malate & $4.7 \pm 0.7$ & $3.4 \pm 0.4$ & $5.1 \pm 0.3$ & $3.7 \pm 0.4$ \\
\hline $\begin{array}{c}\text { Other } \\
\text { compounds }\end{array}$ & $12.8 \pm 0.7$ & $5.7 \pm 0.4$ & $16.4 \pm 0.3$ & $7.0 \pm 0.4$ \\
\hline $\begin{array}{c}\text { Sucrose/ } \\
\text { Hexoses }\end{array}$ & 11.6 & 36.7 & 13.6 & 38.1 \\
\hline $\begin{array}{c}\text { Control/ } \\
\text { fertiliz }\end{array}$ & 1.29 & 4.07 & 1.24 & 3.36 \\
\hline
\end{tabular}

Previously it was noted that oxygen absorption by ETC is directly related to the regulation of reductive pentosephosphate pathway. This is proved by the experiments cited in the work [13]. In the work when the reagent of the Mehler reaction, methyl vilogen, was added to isolated chloroplasts up to $95 \%$ of ascorbate acidified after 1 minute in the light. Mehler reaction activation by methyl vilogen led to inhibition of reductive pentosephosphate pathway of oxygen.

The connection between $\mathrm{O}_{2}$ photo absorption and the Calvin cycle functioning is indicated in many other works. For example, experimenting with intact algae, Radmer \& Olinger [14] came to a conclusion that $\mathrm{CO}_{2}$ and $\mathrm{O}_{2}$, being final acceptors of electrons, guarantee electron beam functioning in ETC of chloroplasts. Measuring simultaneously chlorophyll fluorescence and oxygen exchange of cells by the method of mass spectrometry, they demonstrated that fluorescence induction curves and electron transport practically do not depend on presence of $\mathrm{CO}_{2}$ in the environment medium but change drastically if $\mathrm{O}_{2}$ is eliminated from the medium. Elimination of $\mathrm{O}_{2}$ from the medium containing $\mathrm{CO}_{2}$ leads to prolongation of the lag period of $\mathrm{CO}_{2}$ fixation. Thus, in case of absence of $\mathrm{O}_{2}$ for additional loading of the ETC of chloroplasts photosynthetic fixation of $\mathrm{CO}_{2}$ in the Calvin cycle has to shift to a new stationary level in order to provide reorientation of the clear $\left(\mathrm{O}_{2}\right.$ free $)$ electron beam in the ETC of chloroplasts from $\mathrm{O}_{2}$ reduction to $\mathrm{CO}_{2}$ reduction.

Once $\mathrm{O}_{2}$ concentration is increased, the speed of its absorption rises, and notably, saturating concentrations were higher with a higher photochemical activity of chloroplasts [15]. Oxygen photoabsorption seems to have greater significance for dark-light transition. Once the light is switched on when dark reactions of $\mathrm{CO}_{2}$ reduction are not prepared yet, pseudocyclic electron transport connected to $\mathrm{CO}_{2}$ absorption is initiated in chloroplasts. Consequently, photodamage of the photosynthetic apparatus is tightly connected to PR function and glycolate metabolism. This fact becomes more obvious taking into account that chlorophyll photosynthesis is tightly related to glycolate metabolism.

Thus, PR is the function of the photosynthetic apparatus protection against damage by illumination. However, this role is reduced in many publications to provision of blank loading of chloroplast ETC in the absence of $\mathrm{CO}_{2}$. It is presumed that in the bright light if stomata are closed (for example, in case of water deficiency) $\mathrm{CO}_{2}$ concentration is rapidly reduced in the inner space of the leaf to carbon dioxide compensation point. Under these conditions chloroplast "idles". There is another point of view [16], according to which if oxygen concentration is sufficient for the Mehler reaction (and not RUBISCO), it intercepts electrons in chloroplast ETC and thus prevents secondary reduction of redox agents which is characteristic of anaerobiosis.

The suggested hypothesis of photosynthesis regulation presupposed the existence of another important role of photooxidative processes in the autotrophic cell activity substrate provision of the donor leaf protein and pigment biosynthesis as these processes are the quickest and the most direct way of organic acid and aminoacid production from primary products of photosynthesis. Relatively speaking, this point of view has long been known by photosynthesis researchers $[17,18]$ but these statements were not related to admittance of necessity to convert glycolate cycle into the Calvin cycle. In case of inhibition of sugar efflux from mesofyll cells the reduction of glycolate metabolism products becomes practically impossible and these compounds must either be accumulated in the cell or recovered.

When the plants are kept under the conditions reducing photo oxidating processes (oxygen concentration 1\%) and chloroplast ETC is not carbon dioxide loaded (absence of $\mathrm{CO}_{2}$ ) there may be observed photosynthetic apparatus malfunctioning. It is interesting that even without taking into account the mechanism of $\mathrm{CO} 2$ and $\mathrm{O}_{2}$ influence on photo inhibition there was a point of view [17] according to which a certain minimal level of oxygen metabolism is necessary for the leaf to dissipate significant excess of light energy. It is still not clear what mechanisms regulate that DAR disturbance changes the direction of oxygen photosynthetic metabolism. The reduction of the leaf export function (removal of a fragment of fruit) is accompanied by photosynthesis transport 
product inhibition, sucrose, and activation of organic and amino acids production caused by the nitrogenous nutrition increase. It is known that the nitrogenous nutrition increase leads to increment in leaf weight. There is a point of view in agronomic practices according to which inhibition of sugar efflux from the leaves after the nitrogenous nutrition increase is related to nitrogenous metabolism intensification when a great amount of sugars is needed for amino acid synthesis. And under these conditions there are no free sugars remaining for the export from the leaf. As non-carbohydrate trend of photosynthesis is related primarily to nitrogen compound production (mostly amin oacids), the following stage of our research was dedicated to defining the role of mineral nitrogen in photosynthesis regulation and DAR. For that purpose the day before the experiment the plants were nourished with either potassium nitrate or the equivalent amount of reduced nitrogen in the form of urea.

As it was established [18], the reason of inhibition of sugar efflux from the leaf and intensification of non-carbohydrate trend of its photosynthesis with nitrogen nutrition level increment was not in nitrogen but in nitrate nitrogen. Plant nourishing with the equivalent amount of nitrogen in the form of urea did not lead to such an effect. This phenomenon was more obvious when the illumination and $\mathrm{CO}_{2}$ concentration were decreased [19]. All this data indicated regulatory relation between nitrite reduction processes in chloroplast ETC and carbon metabolism. As glycolate production in the transketolase reaction of the Calvin cycle needs an active oxidizing agent, it was supposed that this is the incomplete nitrite reduction product in chloroplast ETC.

\section{The Role of the Apoplast in Regulation of Assimilate Transportation from the Leaf}

When nitrogen and PCM ratio was studied, it was discovered that nitrate activity reduced export and, consequently, synthesis of sucrose but ${ }^{14} \mathrm{C}$ inclusion in hexoses (glucose and fructose) relatively increased. Consequently, there was suggested a hypothesis that this was the effect of the apoplastic invertase activity which hydrolysed sucrose preventing its export from the leaf. In order to verify this working hypothesis a special method of study of content of labelled products of photosynthesis in leaf apoplast was elaborated [20]. The essence of the method was as follows. A leaf or part of a shoot (for example, of the linen flax) not removed from the plant after short-term exposition to the light in ${ }^{14} \mathrm{CO}_{2}$ was rapidly cut off and placed to "the pressure chamber" after infiltration with water.

The end of the shoot or leaf-stalk was put outside through a conical rubber plug. Then the pressure on the leaf equal to its water potential was created inside the "chamber" and infiltrated fluid was extracted from the leaf and collected from the leaf-stalk with absorbent paper placed outside up to the end of its excretion. The collected fluid was dropped on paper chromatogram and after two-dimensional distillation and exposure in radiographic film 14C concentration in each of the labelled compounds was estimated.
This work was initiated by the article where the efflux of labelled $11 \mathrm{C}$ assimilates from bean leaves was studied. The kinetics of the upward label transport from the leaf had two components - rapid and slow, and that of the downward transport - only the slow component. The authors came to a conclusion that assimilates travel from the phloem to the stem apoplast and are carried up by the xylem stream of water. As the intensity of water stream is two or three sequences higher than that of photosynthesis, the speed of upward transport of labelled substances dissolved in water was significantly higher.

We chose the linen flax as the subject of research to verify this supposition. During the period of rapid growth the linen flax shoot has multiple equal mature assimilate donor leaves and only two assimilate acceptors - growing apex and roots. The shoot apex at this time actively consumes assimilates as it grows at the speed up to $4 \mathrm{~cm} /$ day. Labelled carbon inclusion into mature leaves in the middle part of the shoot (donor part) allowed observing the state of assimilates both in the course of their metabolism in donor leaves and transport to other parts of the shoot (including mature donor leaves which were simultaneously "alien" assimilate acceptors).

The results of these experiments confirmed the data obtained. The first minutes after "the gulp" the number of ${ }^{14} \mathrm{CO}_{2}$ labelled assimilates in the upper part of the shoot was significantly bigger than that in the lower part. When "the alien" assimilates got to the apoplast of the upper leaves, they were not recovered (like in young leaves) but were loaded in their apoplast for the second time into the ending of the phloem and re-exported (Figure 1). As a result the concentration of labelled carbon after a day reduced in mature leaves and grew in the apex.

The fact that these "alien" assimilates, when transporting along the phloem, may re-enter the apoplast (which can be repeated many times) can lead to formation of a certain mobile collectivized reserve of assimilates in the whole plant apoplast which is dynamically rearranged among organs in accordance with their transpiration. The general vector of assimilate movement in the apoplast goes up and in phloem - down.

The discovery of such a mechanism of assimilate distribution throughout the plant clarifies the nature of many previously known effects. For example, the lack of assimilate exchange among mature leaves, "the harsh law" is explained not by the prohibition of "alien" assimilate inclusion into mature leaves but their further re-export. The collectivized reserve of assimilates formed in the apoplast may fulfil the function of the signal reflecting DAR change in the whole plant. Scientists have not been able to find the "signal" and the mechanism of its activity for many decades.

The nature of a well-known law, according to which most assimilates from the upper leaves are sent to the head and those form the lower leaves - to the root, has become clear. This happens due to the fact that the upper leaf assimilates have more chances to end up in the stem apoplast and move to the upper 
part of the shoot as each sieve tube of the phloem is washed outside by intensive reversed flow of transpirational water. For the same reason it is easier for the lower leaf assimilates to reach the roots as they do not have to "go" against the flow of transpirational water.

\section{Relationship between Nitrogen and Carbon} Metabolism in Regulation of Assimilate Transport from the Leaf

The research of ${ }^{14} \mathrm{C}$ among the labelled photosynthesis products in the apoplast demonstrated that under the influence of nitrate nutrition sucrose/hexose ratio in the apoplast decreased more significantly (4 times) than in mesofyll (only $27 \%$ ). It is characteristic that such a regularity was observed not only in ${ }^{14} \mathrm{C}$-donor part of the shoot (exactly where $14 \mathrm{CO} 2$ was assimilated) but also in the leaves that stopped growing in the shoot upper part where "the alien" labelled assimilates were delivered by water flow. Thus, long-distance sucrose transport in the leaf might be hindered by its hydrolysis in the apoplast and this process may be an important factor influencing the production process. In order to find out whether nitrate has direct impact on sugar efflux, the solutions of various substances (water, urea, $\mathrm{KNO}_{3}, \mathrm{NH}_{4} \mathrm{NO}_{3}$ ) were introduced into linen flax shoot through a special installation [21]. Preliminary tests showed that plants could live in such an installation in the summer without visible damages for several days.

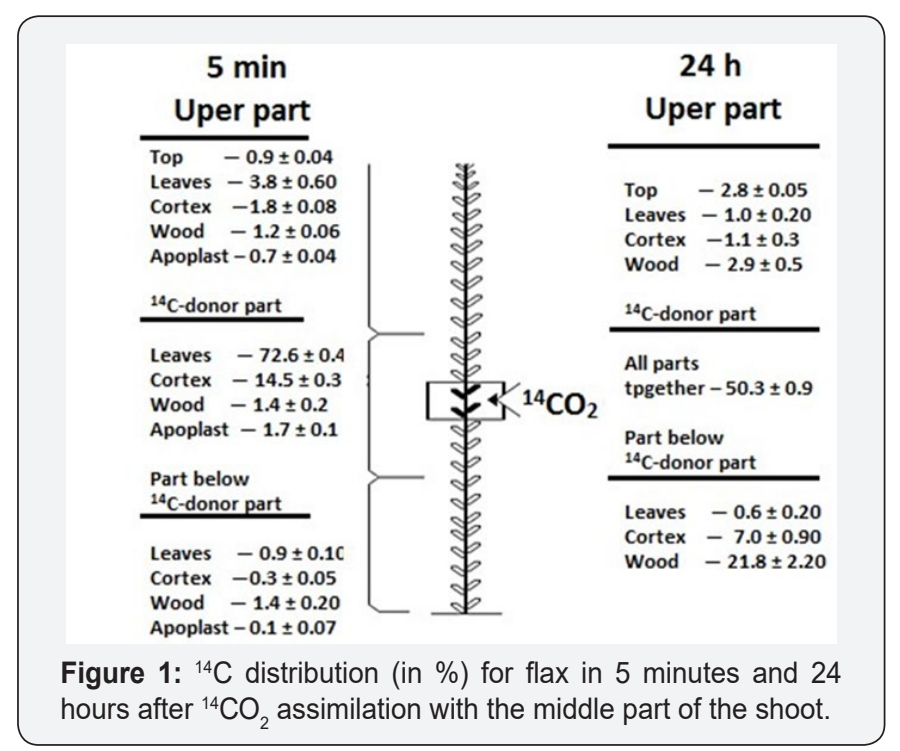

When transport of the labelled assimilates from the middle part of the linen flax shoot was studied, significant differences in labelling pattern between the upper and the lower part of the shoot was detected in experimental plants 3 hours after ${ }^{14} \mathrm{CO}_{2}$ assimilation (Figure 1). Nitrates suppressed significantly assimilate downward movement (along the phloem) and stimulated upward movement while labelled assimilates were "delayed" in the donor stem. It seemed that "nitrate" plants did not only have poor export of assimilates from mesophyll cells but the assimilates that had already left those cells moved slower down the stem phloem. In order to find out in which of the compounds the label was concentrated in model experiments with linen flax, the dynamics of ${ }^{14} \mathrm{C}$ distribution among soluble products of the leaf photosynthesis was analysed. It was discovered that the dynamics of labelling pattern in sucrose of "nitrate" plants differed significantly from that of control plants (administration of water into the shoot). During short expositions (3 minutes) after ${ }^{14} \mathrm{CO}_{2}$ assimilation "nitrate" plants, as a rule, had lowered ${ }^{14} \mathrm{C}$ content in sucrose [21].

After 30 minutes, when the label of primary products of photosynthesis was found mainly in sucrose (which moved from mesophyll cells to the apoplast and started transporting to phloem endings but was still inside the leaf), the content of the label in sucrose of all plants increased and levelled.

Then the plants, to which water or urea had been administered, successfully exported sucrose outside the leaf and labelling pattern in sucrose decreased significantly. "Nitrate" plants had difficulty exporting sucrose outside the leaf at this stage. As a result the label from the primary products of photosynthesis occurred in sucrose and sucrose itself could not be exported and was accumulated in the leaf. The question then arose as to where sucrose could localize within the leaf. To clarify that radioautographs of linen flax leaves after ${ }^{14} \mathrm{CO}_{2}$ assimilation were obtained. The radio autographs showed [21] that the major part of control plant label was concentrated in large conducting bundles of the leaf while that of "nitrate" plants - in the space between them. This signalled the difficulty in sucrose exposure to the phloem sieve tubes.

Such a difference demanded detailed analysis of the ultrastructure of leaf cells. Normally in terminal complexes of the apoplast plant phloem assimilates move from mesophyll cells to the apoplast space and then are received by phloem companion cells. These cells are usually poorly vacuolated (have singular small vacuoles) and their plasmalemma has [22] a lot of folds (protuberances) which increase its surface. Sucrose is "loaded" to phloem companion cells on this membrane (due to active energy-dependent transport) whilst large gradient of sucrose concentration is created. Then sucrose moves through plasmodesms from companion cells to sieve tubes where, as it is believed, [23] it moves passively in direction of decreasing gradient of concentration to consuming organs.

Unlike in control, administration of nitrates to the apolast caused intensive vacuolization of the companion cells [23]. Notably, it seemed that the companion cells "protecting" their cytoplasm from osmotic stress captured extracellular apoplast fluid with high concentration of sucrose that was transported to cytoplasm by means of endocytosis. Singular vesicules formed one big vacuole where multiple residues of membranes were preserved. All this implies that at the stage of sucrose movement through companion cells (or sieve tubes) there are mechanisms 
of efficient regulation of long-distance transport of sucrose. Probably, the important role in regulation of the discovered phenomena is played by callose production in the pores of phloem tubes [24] whose synthesis might be influenced by nitrogen oxide activated by salicylic acid [25].

The pores of sieve tubes are clogged, possibly, at the stage of the first encounter of nitrates in the lower part of the shoot. $14 \mathrm{CO} 2$ assimilation with the middle part of the shoot in these experiments was complete 30 minutes after introducing the nitrate solution into the shoot. During this period due to blocked pores of the phloem in the lower part of the stem it was overloaded with ${ }^{12} \mathrm{C}$-sucrose and in these conditions ${ }^{12} \mathrm{C}$-sucrose had no space for transportation. That is why the difference between control and experiment concerning the radioactivity of the lower part of the shoot was very big (Figure 2). Accumulation of the labelled sugars in the donor (including the stem) part of the shoot led to their successful upward transport with transpirational water. The latter activated the utilization of these sugars in the top where not only sugars but also nitrates were accumulated.

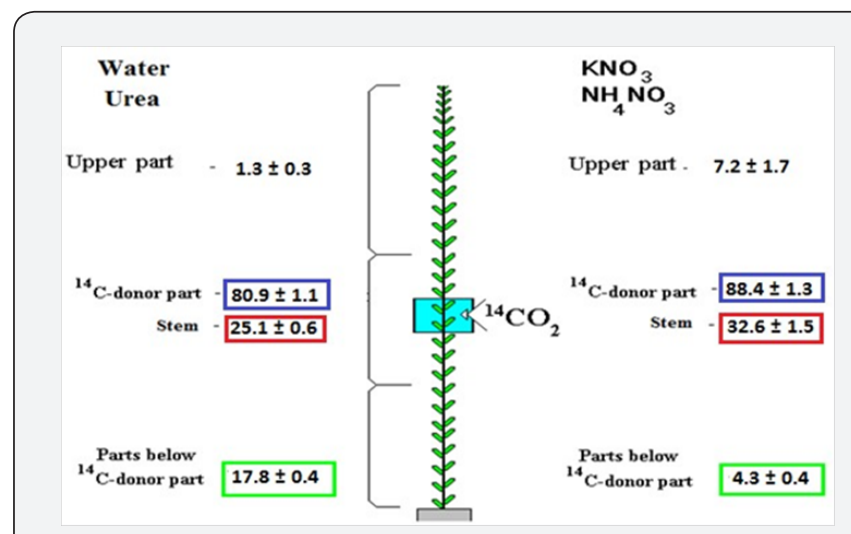

Figure 2: ${ }^{14} \mathrm{C}$ pattern in flax (Linum usitatissimum L.) after ${ }^{14} \mathrm{CO}_{2}$ assimilation with the middle part of the shoot.

Role of Apoplastic Invertase in the Link between Photosynthesis and Stomatal Regulation

The significant reduction of labelled sucrose/hexose ratio not only under the influence of nitrates but any other factors suppressing photosynthesis [26] allowed us to presume regular participation of the apoplastic invertase both in sucrose hydrolisis and its export from the leaf. Consequently, a number of experiments on plant genetic transformation in relation to the apoplastic invertase were conducted. Indeed, the administration of an additional gene of the apoplastic invertase to potato plants (D-33 type) demonstrated strongly marked non-carbohydrate trend of photosynthesis. In comparison to the initial form the intensity of ${ }^{14} \mathrm{CO}_{2}$ fixation and relative inclusion of ${ }^{14} \mathrm{C}$ into sucrose of B-33 type plants was 1,5-2,0 times lower. The labelled sucrose/hexose ratio was 4 times lower. All this signalled strongly inhibited export of sugars from the leaves and insufficient supply of the root system with assimilates. This might also cause the reduction in growth processes in the aerial parts of plants.
Table 4: Effect of irradiance and suppression of the apoplastic invertase gene on leaf physiological characteristics in wild type tomato plants and in genetically transformed plants.

\begin{tabular}{|c|c|c|c|c|}
\hline Characteristic & Wild Type & Lin8-RNAi & $\begin{array}{l}\text { Wild } \\
\text { type }\end{array}$ & Lin8-RNAi \\
\hline $\begin{array}{c}\text { Photon flux } \\
\text { density, } \mu \mathrm{mol} / \\
\left(\mathrm{m}^{2} \mathrm{~s}\right)\end{array}$ & $1556 \pm 32$ & & $771 \pm 58$ & \\
\hline 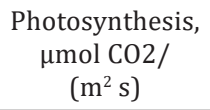 & $21.60 \pm 0.70$ & $23.49 \pm 0.51$ & $\begin{array}{c}17.75 \pm 0 \\
56\end{array}$ & $20.51 \pm 0.97$ \\
\hline $\begin{array}{c}\text { Transpiration, } \\
\text { mmol H2O/ } \\
\left(\mathrm{m}^{2} \mathrm{~s}\right)\end{array}$ & $8.08 \pm 0.32$ & $8.31 \pm 0.36$ & $\begin{array}{c}6.97 \pm 0 \\
26\end{array}$ & $9.44 \pm 0.17$ \\
\hline $\begin{array}{c}\text { Transpiration/ } \\
\text { photosynthesis } \\
\text { ratio }\end{array}$ & $374 \pm 7$ & $354 \pm 18$ & $393 \pm 8$ & $460 \pm 37$ \\
\hline $\begin{array}{c}\text { Stomatal } \\
\text { conductance, } \\
\mu \mathrm{mol} \mathrm{CO}_{2} /\left(\mathrm{m}^{2} \mathrm{~s}\right)\end{array}$ & $322 \pm 17$ & $303 \pm 9$ & $271 \pm 12$ & $375 \pm 27$ \\
\hline $\begin{array}{l}\text { Intraleaf } \mathrm{CO}_{2} \\
\text { concentration, } \\
\text { ppm }\end{array}$ & $232 \pm 5$ & $232 \pm 5$ & $246 \pm 2$ & $276 \pm 10$ \\
\hline
\end{tabular}

The experiments on tomato plants, in which the apoplastic invertase gene, on the contrary, was inhibited by RNA interference (Lin8-RNAi form) showed [27] that the character of genetic transformation influence of photosynthesis depended on assimilate demand of the accepting organs. When the experimental plants were grown in a vase with a limited volume of soil at the initial stage of growth and mineral nutrition supply was high, Lin8-RNAi plants had higher photosynthesis in comparison to wild plants (Table 4). As mineral nutrition reserves became exhausted, the photosynthesis of wild plants reduced, especially in Lin8-RNAi form. The analysis of 14C pattern among products of photosynthesis showed the reduction of ${ }^{14} \mathrm{C}$ inclusion into glucose and fructose in Lin8-RNAi which resulted in increase in sucrose/hexose ratio. Soil application of the plants with nitrates intensified non-carbohydrate trend of photosynthesis but it was less prominent for the transformants. Thus, the apoplastic invertase inhibition had the opposite impact on the PCM in comparison to additional administration of the ferment.

The simultaneous measurement of $\mathrm{CO}_{2}$ exchange and transcription with IR gas sensor detected small increase in photosynthesis of Lin8-RNAi plants as well as $\mathrm{CO}_{2}$ transpiration and concentration within the leaf. Double reduction of illumination for 30 minutes led to reduction of photosynthesis in both genotypes (Lin8-RNAi and Wild), however, the transpiration of the wild type plants reduced and that of Lin8-RNAi increased.

This data was the critical point in understanding of photosynthesis regulation mechanism. The researchers of plant gaseous exchange know that photosynthesis and transpiration always change simultaneously. Agu Laisk believed [28] that while studying the impact of some unfavourable factor on the plant it is 
not necessary to measure photosynthesis. It is enough to measure transpiration. If transpiration is reduced, photosynthesis is likely to be reduced too. The growth of transpiration intensity in transformants with the inhibited gene of apoplastic invertase put this statement in question.

In order to understand the mechanisms of invertase activity influence on photosynthesis and transpiration (which are interrelated) it is necessary to consider the mechanism of stomatal apparatus functioning [29]. The reduction of invertase activity in the leaf apoplast must lead to reduction of extracellular water activity osmolality as in case of sucrose hydrolysis instead of one molecule there appear two osmotically active molecules of glucose and fructose.

For many years sugars have played an important role in interpretation of the mechanism of the guard cell stomatal movement. The well-known traditional theory (hydrolysis of starch into sugars during stomatal opening and production of starch during stomatal closure) presupposed the osmotic role of sugars inside the guard cells sufficient for creation of the necessary turgor during stomatal opening. Due to lack of methods at that time this theory was only partially verified for starch and not verified at all for sugars. The concept of the guard cells that existed for over 100 years, basing upon the change of osmolality within the guard cells from the thermodynamic point of view was erroneous. It is a well-known fact that any living system is an open system and all the changes within it are determined by interaction with the environment. For stomatal cells it is the osmolality of the extracellular environment - apoplast. The traditional theory was rejected after the discovery of $\mathrm{K}+$ accumulation in the guard cells which turned out to accompany stomatal opening. But the potassium theory was declined too due to the discovery according to which $\mathrm{K}+$ circulates between the leaf and the roots as a shuttle transporting nitrate ion from the roots to the leaves [30]. Moreover, it was discovered [31,32] that red colour, that reinforces carbohydrate trend of photosynthesis [33], causes the increase in stomatal cleft size without changing the content of starch and $K+$. It is worth mentioning that potassium activity was considered by the researchers to take place inside the guard cells.

L.T. Karpushkin and co-authors were the first to consider the increase of extracellular (apoplast) fluid osmolality as the regulatory role in the mechanism of stomatal closure. And this happens, according to the authors, due to growth of xylem solution concentration in the cell walls which is increased approaching the guard cells, where the main evaporation of water takes place. The proposed idea of the importance of apoplast fluid osmolality of stomatal closure was proved 16 years later in works $[34,35]$ in relation to sucrose concentration in the apoplast.

The authors demonstrated that sucrose in the apoplast of the guard cells had significant osmotic influence on stomatal opening. According to the authors' hypothesis sucrose accumulation in the apoplast is the signal which causes stomatal cleft reduction and is a mechanism for reduction of stomatal conductance with high intensity of transpiration. However, the authors did not provide any explanation, even hypothetical, of the nature of this signal, though it is obvious that it is not sucrose itself, as a metabolite that influences stomatal opening but osmolality of the outer water environment.

The obtained data on gaseous exchange of tomato plants transformed with the apoplastic invertase gene makes it possible to suggest the osmotic mechanism of stomatal conductance regulation as the key factor in regulation of the whole photosynthetic function of the plant. The situation in the latter experiment develops in the following way (Figure 3). The formation of the products of photochemical reactions in chloroplasts reduced in conditions of reduced illumination.

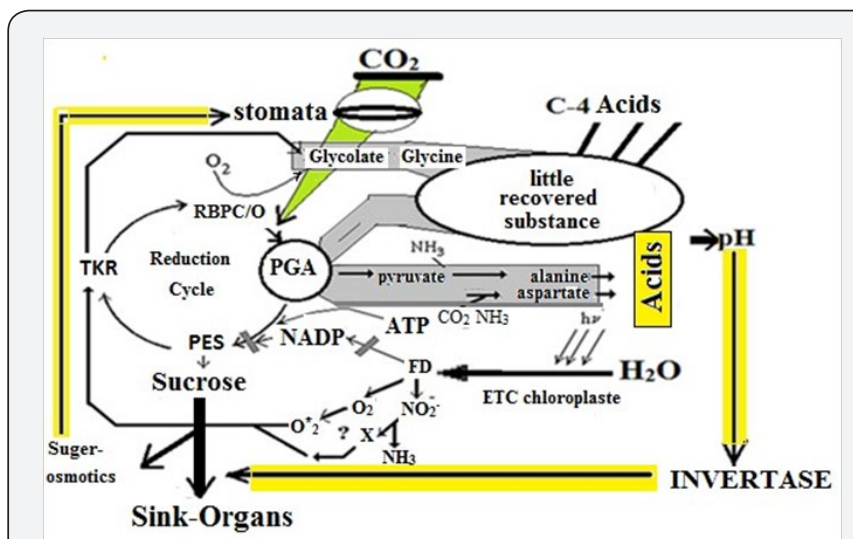

Figure 3: The scheme of photosynthetic carbon metabolism regulation in case of disturbance of dark and light photosynthesis process ratio in the whole plant

As a result a part of primary products of photosynthesis cannot be reduced to sugars and remains in the form of oxygenated products. As carbon flow through the glycolate passage makes about half of photosynthesis Warburg effect index in (Table 1), it is a big amount of substances that cannot be utilized within the cells and is accumulated in vacuoles and extracellular environment of mesophyll cells. Excessive acidity of the plants not transformed with the invertase gene increases its activity. Further hydrolysis of sucrose not only hinders its export from the leaf but also increases water environment osmolality as one mole of sucrose is replaced by two moles of hexoses. This osmolality is increased more significantly when the solution moves towards stomatal cavity of the leaf where water evaporation takes place. High outer osmolality closes the stomata and increases the resistance of $\mathrm{CO}_{2}$ diffusion to the leaf, which leads to photosynthesis reduction. Thus, normally the apoplastic invertase and stomata put into effect inverse regulatory relationship between photochemical processes in chloroplasts with export of sugars from the leaf and photosynthesis intensity.

It does not occur in case of the plants with inhibited invertase because sucrose is successfully loaded into the phloem without being hydrolysed by invertase. As a result the apoplast osmolality 
after illumination reduction reduces even more (the apoplast contains neither sucrose nor hexoses). The turgor of stomatal guard cells grows and additional opening occurs. This was observed in our experiments when illumination was reduced.

In order to check a hypothesis the following experiments with the plant light pattern change were conducted. When illumination is increased the number of products of photochemical reactions in chloroplasts grows, $\mathrm{CO}_{2}$ assimilation and sugar production are intensified. And vice versa, when illumination is decreased, primary products of $\mathrm{CO}_{2}$ fixation cannot continue metabolising without sufficient supply of products of chloroplast photochemical reactions and, consequently, are accumulated in mesophyll. In both cases the existing mechanisms must switch on to normalise such a situation.

In order to check this supposition in the phase of initial blossom of potato when assimilate acceptors, tubers, started developing, 5 days prior to the experiment a part of the plants was shadowed with a gauze cloth which reduced illumination up to $50 \%$. On the day of the experiment half of the shadowed plants were exposed to direct sunlight for 30 minutes and the light plants, on the contrary, were shadowed (for 30 minutes as well). Thus, plants of four different variants of illumination were received [36]. The photosynthesis of all the plants was estimated in conditions of the light which they were exposed to at the moment of measurement (direct sunlight or $50 \%$ shadowing).

The intensity of 3-minute fixation of ${ }^{14} \mathrm{CO}_{2}$ in experimental plants depended directly on illumination. The photosynthesis of the plants shadowed for 5 days was reduced to $52 \%$ in comparison to control mark. But if plants had been shadowed for 30 minutes only, their photosynthesis reduced to $70 \%$. Simultaneously, if shadowed plants were exposed to direct light, the intensity of photosynthesis grew dramatically. Notably, photosynthesis of the leaves adapted to high level of illumination and then suddenly shadowed reduced more significantly than that of the plants shadowed for 5 days; moreover, when illumination was increased, the latter demonstrated elevated ${ }^{14} \mathrm{CO}_{2}$ fixation which even exceeded the control level. The analysis of ${ }^{14} \mathrm{C}$ pattern among products of photosynthesis revealed significant differences in formation of carbohydrate and non-carbohydrate compounds in the leaves of different variants of plants [37].

The illumination conditions had authentic influence on sucrose synthesis. Thus, in the direct sunlight there was observed the highest ${ }^{14} \mathrm{C}$ inclusion into sucrose (in relation to total radioactivity of low-molecular compounds). Long-term (for 5 days) shadowing reduced this index, however, total amount of free sugars (sucrose, glucose, fructose and oligosaccharides) as percentage of radioactivity of all the labelled compounds in the leaves of this variant was higher. The lowest intensity of sucrose production (and sugars in general) was detected when the plants adapted to high level of illumination were shadowed for a short period of time (30 minutes). Taking into account the fact that the plants of this variant had the lowest intensity of ${ }^{14} \mathrm{CO}_{2}$ assimilation (only $30 \%$ of control level), their sucrose synthesis was thrice lower. Sucrose/hexose ratio of all the shadowed plants reduced 3.6-4.1 times irrespectively of whether they were adapted to light or not. The greatest reduction of this index was observed when plants were suddenly shadowed for 30 minutes and the smallest when the leaves shadowed for 5 days were exposed to light for 30 minutes.

The radioactivity of glycolate metabolism products in all plants (except the control one) was reduced, while serine/ glycine index was reduced in comparison to control for all the shadowed plants. ${ }^{14} \mathrm{C}$ inclusion into four-carbon compounds (aspartate, malate) changed in opposite directions depending on illumination in which the leaf fixed ${ }^{14} \mathrm{CO}_{2}$. Thus, the radioactivity of these compounds in the shadowed plants (5 days or 30 minutes) grew in comparison to the control level (especially in case of sudden shadowing), but when the plants shadowed for 5 days were exposed to bright light, their radioactivity reduced in comparison to the control level. This might be related to aspartate and malate reserve accumulated during the previous shadowing. As a result the correlation between labelled products of the glycolate passage and four-carbon compounds reduced in the plants shadowed for 5 days about 2 times; that in the plants shadowed for 30 minutes - 4 times, while that in the plants shadowed and then exposed to light grew about 1.5 times in comparison to the control level.

Elevated carbohydrate trend of photosynthesis in high illumination signals that the products of the glycolate passage are successfully reduced to sugars. This means that illumination increase leads to the glycolate cycle closure with the CalvinBenson cycle. And, vice versa, under conditions of illumination decrease and deficiency of NADPH produced in chloroplasts carbon return of the glycolate passage products to pentose phosphate cycle is reduced and the major part of these compounds remains in oxidized condition.

If there is a big number of organic acids and amino acids in the cell, pH is likely to be reduced not only in the cytoplasm but also in the apoplast of the mesophyll cells. The apoplast acidification activates sucrose invertase and hydrolysis. As a result the osmolality of the apoplast fluid, whose level rises approaching the stomatal cleft, is increased. The increase of osmolality of the environment around the guard cells causes turgor reduction, stomatal closure and rise of resistance of $\mathrm{CO}_{2}$ diffusion to the leaf, which is accompanied by photosynthesis intensity reduction [38-45].

\section{Conclusion}

Thus, there is a regulatory complex in the leaf that unites photochemical processes in chloroplasts, PCM in the cell, apoplastic invertase and stomatal functions into one mechanism. It can be presumed that this mechanism reacts to the change of illumination intensity, nitrogen (nitrate) nutrition level, 
growth processes activity in assimilate-accepting organs and optimises the whole photosynthetic function of the plant. The key trigger mechanism in any case is, presumably, the degree of use of products of photochemical reactions in chloroplasts. What is photosynthesis? It is three stages of events: production of chloroplast" reduction ability", carbon dioxide fixation with organic acid production and reduction of these acids to sugars. If the number of photoproducts is sufficient, the acids are not accumulated and the extracellular water environment is neutral ( $\mathrm{pH}-7.0)$. When the reduction of acids to sugars is limited, the extracellular environment is acidified and the stomatal mechanism of reduction of $\mathrm{CO}_{2}$ diffusion in the leaf is triggered in the leaf apoplast through hydrolysis of invertase sucrose.

When the concentration of nitrates in the leaf rises, the competition of nitrite for electron in chloroplast ETC is increased. As a result, PCM reacts to nitrates like to shadowing and, consequently, all previously described changes occur. When the efflux of assimilates from the leaf is inhibited (for example, because of reduction in activity or quantity of accepting organs), sucrose loading to the overloaded phloem will be hindered. The rise of its concentration in the apoplast will cause substrate activation of invertase, intensification of sucrose hydrolysis and further stomatal closure. The excess of sugars will intensify the supply of the root system with products of photosynthesis, which will lead to greater increase in administration of nitrates to the leaves and all further events, as it was previously described.

The produced hexoses will return in large quantities to mesophyll cells hindering the metabolism of triosophosphates translocated from chloroplasts, which will lead to the Mehler reaction activation and production of glycolate of transketolase origin (including under the influence of additional nitrates). Carbon of these products of glycolate metabolism cannot return to the Calvin-Benson cycle and will replenish the pool of acids with further influence on the apoplastic invertase and closure of the stomatal cell. Moreover, hexose accumulation in cytoplasm and non-return of non-organic phosphate to chloroplasts will intensify starch synthesis in them.

The experiments on corn, like those on potato, demonstrated the analogical reaction of C-4 plant leaves to illumination change. However, unlike in C-3 type plants, regulatory acidification of the apoplastic fluid in C-4 type plants is presumably implemented by the sheath of C-4 acid transferred from mesophyll. When their metabolisation is inhibited in the cells of the sheath, they are accumulated both in the cells and the apoplast. The obtained data suggests that the products of glycolate metabolism participate there as well. However, this needs to be proved.

The above-mentioned data signals that there is a unique complex mechanism of the photosynthetic function regulation in plants, which, though not having direct contacts between single elements, unifies the functions of the processes occurring in remote compartments of the leaf. The unifying factor in this regulation is mass transport of the substance throughout the plant. This complex includes the electron transport chain of chloroplasts, chloroplast stroma with $\mathrm{CO}_{2}$ assimilation and production of sugars in the Calvin cycle, apoplastic invertase in mesophyll and stomatal apparatus of the leaf. The latter is the executive organ that controls transport flow of photosynthetic products from the leaf to accepting organs, which optimises dark and light processes in the leaf and protects photosynthetic apparatus of the plant from photodamage.

\section{References}

1. Popov KI (1959) On the ecology of plants damaged in the phase of sprouting leaf-chewing insects. Abstracts environmental conference at the University of Kiev Part I Kiev.

2. (1977) Lenz F Einflù $\beta$ der Frucht auf Photosynthese und Atmun. Einflù $\beta$ der Frucht auf Photosynthese und Atmun g Ztschr. Pflanzenenernahr. Und Bodenk Bd 140: 51-61.

3. Chikov VI, Isfandiyarov NI (1978) Effects of the Rate of Assimilate Efflux on the Ratio between Some Components of Plant Gas Exchange. Gorky, USA, p. 182.

4. Shabashvili Э3, Chikov VI (1984) Structural and functional response of chloroplasts of cotton leaves to change the donor-acceptor relationship in the plant. Sov Plant Physiol 39: 480-485.

5. Chikov VI, Yargunov VG, Fedoseeva EZ, Chemikosova SB (1982) Effects of Correlation between Assimilate Production and Usage on Functioning of the Photosynthetic Apparatus in Plants. Sov Plant Physiol 29: 1141-1146.

6. Chikov VI, Chemikosova SB, Bakirpva GG, Gazizova NI (1984) Influence of removal of a portion of spike or leaves on assimilate transport and photosynthetic productivity in spring wheat. Sov Plant Physiol 31(3): 475-481.

7. Tolbert NE (1979) Glycolate metabolism by higher plants and algae. Photosynthesis II 6: 338-352.

8. Chikov VI, Bulka ME, Yargunov VG (1985) Effect of removal of reproductive organs on photosynthetic ${ }^{14} \mathrm{CO}_{2}$ metabolism in cotton leaves. Soviet Journal of Plant Physiology 32: 1055-1063.

9. Chikov VI (1987) Photosynthesis and Transport of Assimilates. Nauka, Moscow, Russia.

10. Eickenbusch JD, Beck E (1973) Evidence for involvement of 2 types of reaction in glycolate formation during photosynthesis in isolated spinach chloroplasts. FEBS Letters 31(2): 225-228.

11. Asami S, Akasava T (1975) Biosynthetic mechanism of glycolate in Chromatium II. Enzymic mechanism of glycolate formation by a transketolase system. Plant and Cell Physyol 16(5): 805-814.

12. Takabe T, Asami S, Akazawa T (1980) Glycolate formation catalyzed by spinach leaf transketolase utilizing the superoxide radical. Biochemistry 19(17): 3985-3989.

13. Foyer Ch, Rowell J, Walker D (1983) Measurement of the ascorbate content of spinach leaf protoplasts and chloroplasts during illumination. Planta 157(3): 239 -244.

14. Radmer R, Ollinger O (1980) Fluorescence and gas exchange in Scenedesmus. Abst $5^{\text {th }}$ Intern, Congr Photosynth, Halkidiki, Greece, p. 459.

15. Takahashi M, Asada K (1982) Dependence of oxygen affinity for Mehler reaction on Photochemical activity of chlorplast thylakoids. Plant and Cell Physiol 23(8): 1457-1461.

16. Suzuki K, Ikawa T (1984) Effect of oxygen on photosynthetic " ${ }^{\text {COr }}$ fixation in Chroomonas sp. (Cryptophyta). I: Some characteristics of the oxygen effect. Plant and Cell Physiol 25: 367-375. 
17. Powles SB, Comic G, Louason G (1984) Photoinhibition of in vivo photosynthesis induced by strong light in the absence of $\mathrm{CO}_{2}$ : an appraisal of the hypothesis that photorespiration protests against photoinhibition. Physiol veget 22: 437-446.

18. Chikov VI, Bakirova GG, Ivanova NP, Nesterova TN, Chemikosova SB (1998) A change of photosynthetic carbon metabolism in wheat flag leaf under fertilization with ammonia and nitrate. Physiology and Biochemistry of Cultivated Plants 30: 333-341.

19. Chikov V, Bakirova G (2000) Relationship between carbon and nitrogen metabolisms in photosynthesis. The role of photooxidation processes. Photosynthetica 37(4): 519-527.

20. Chikov VI, Avvakumova NY, Bakirova GG, Belova LA, Zaripova LM (2001) Apoplastic transport of 14C-photosynthates measured under drought and nitrogen supply. Biologia Plantarum 44(4): 517-521.

21. Batasheva SN, Abdrakhimov FA, Bakirova GG, Chikov VI (2007) Effect of nitrates supplied with the transpiration flow on assimilate translocation. Russian Journal of Plant Physiology 54(3): 373-380.

22. Abdrakhimov FA, Batasheva SN, Bakirova GG, Chikov VI (2008) Dynamics of ultra structure changes in sheet plate fiber flax with braking transport assimilate by nitrate-anion. Tsitologiia 50(8): 700710.

23. Kursanov AL (1984) Endogenous Regulation of Assimilate Transport and Source-Sink Relations in Plants. Sov Plant Physiol 31: 579-595.

24. Serova VV, Raldugina GN, Krasavina MS (2006) Salycylic acid inhibits callose hydrolysis and disrupts transport of tobacco mosaic virus. Dokl Akad Nauk 406: 705-708.

25. Zottini M, Costa A, De Michele R, Ruzzene M, Carimi F, et al. (2007) Salicylic acid activates nitric oxide synthesis in Arabidopsis. J Exp Bot 58(6): 1397-1405.

26. Tarchevsky I A (1965) On the relationship between the photosynthetic phosphorylation assimilation of $\mathrm{CO}_{2}$ and other functions of chloroplasts and photosynthetic cells. Biochemistry and biophysics of photosynthesis. Moscow, Nauka, Russia, pp. 305-319.

27. Chikov VI, Akhtyamova GA, Batasheva SN, Mikhailov AL, Khamidullina, et al. (2015) Effect of silencing of the apoplastic invertase gene on photosynthesis in tomato. Russian Journal of Plant Physiology 62(1): 39-44.

28. Laisk AH (1977) Kinetics of Photosynthesis and Photorespiration in C-3-plants. Moscow, Nauka, Russia, p. 196.

29. Poffenroth M, Green DB, Tallman G (1992) Sugar concentrations in guard cells of Vicia faba illuminated with red or blue light. Analysis by high performance liquid chromatography. Plant Physiol 98(4): 14601471.

30. Lips SN (1997) The role of inorganic nitrogen ions in plant adaptation processes. Russ J Plant Physiol 44: 421-431.
31. Talbott LD, Zeiger E (1993) Sugar and organic acid accumulation in guard cells of Vicia faba in response to red and blue light. Plant Physiol 102: 1163-1169.

32. Voskresenskaya NP (1988) Reactions of photoregulation and their contribution to the photosynthetic activity in plants. In: Nichiporovich AA (Ed.), Photosynthesis and Production Process. Moscow, Nauka, Russia, pp. 142-153.

33. Polyakov MA, Karpushkin LT (1981) Humidity of the air above the evaporating surface of leaf mesophyll cells. Analysis of possible reasons for moisture reduction. Sov Plant Physiol 28: 448-460.

34. Lu P, Outlaw WH, Smith BG, Freed GA (1997) A new mechanism for the regulation of stomatal aperture size in intact leaves. Plant Physiol 114(1): 109-118.

35. Outlaw WH, Vlieghere-He XD (2001) Transpiration rate. An important factor controlling the sucrose content of the guard cell apoplast of broad bean. Plant Physiol 126(4): 1716-1724.

36. Chikov VI, Abdrakhimov FA, Batasheva SN, Khamidullina LA (2006) Characteristics of Photosynthesis in Maize Leaves (C4 Plants) upon Changes in the Level of Illuminance and Nitrate Nutrition. Russ J Plant Physiol 63(5): 620-625.

37. Chikov VI (2008) Evolution of Notions about Relationships between Photosynthesis and Plant Productivity. Russian Journal of Plant Physiology 55(1): 131-144.

38. Chikov VI, Mikhailov AL, Timofeeva OA, Khamidullina LA Photosynthetic carbon metabolism.

39. Hall A, Brady CJ (1977) Assimilate source-sink relationships in Carsicum annuum L. II: Effects of fruiting and defloration on the photosynthetic capacity and senescence of the leaves. J Plant Physiol N 5: 771-779.

40. Kursanov AL (1976) Transport as similyatov rastenii, Nauka Moscow. Elsevier, Amsterdam Publishers, Netherlands.

41. Minchin PEH, McNaughton GS (1987) Xylem Transport of Recently Fixed Carbon within Lupin. Aust J Plant Physiol 14: 325-329.

42. Mokronosov AT, Ivanova NA (1971) Specialities of photosynthetic function at the partial defoliation of plants. Sov J Plant Physiol 18: 668676.

43. Moyse A La (1978) photorespiration Photosynthese et production vegetable. In: Costes C (Ed.), Gauthier-Villars, France, pp. 127-146.

44. Myers SC, Ferree DC (1983) Influence of summer pruning and tree orientation on net photosynthesis, transpiration, shoot growth and dry-weight distribution in young apple trees. J Ammer Soc Hort Sci 108: 4-9.

45. Outlaw WH (1983) Current concepts on the role of potassium in stomatal movements. Physiol Plant 59: 302-311. 
This work is licensed under Creative Commons Attribution 4.0 License

DOI: 10.19080/ARTOAJ.2017.04.555659

\section{Your next submission with Juniper Publishers will reach you the below assets}

- Quality Editorial service

- Swift Peer Review

- Reprints availability

- E-prints Service

- Manuscript Podcast for convenient understanding

- Global attainment for your research

- Manuscript accessibility in different formats ( Pdf, E-pub, Full Text, Audio)

- Unceasing customer service

Track the below URL for one-step submission https://juniperpublishers.com/online-submission.php 